\title{
Perceived Stress and Coping Strategies During the COVID-19 Pandemic Among Public Health and Preventive Medicine Students in Vietnam
}

\author{
Truc Thanh Thai (D) \\ Phuc Truong Vinh Le (D) \\ Quynh Ho Ngoc Huynh' \\ Phuong Thi Thu Pham $\mathbb{D}^{2}$ \\ Han Thi Hy Bui ${ }^{3}$ \\ 'Faculty of Public Health, University of \\ Medicine and Pharmacy at Ho Chi Minh \\ City, Ho Chi Minh City, Vietnam; \\ ${ }^{2}$ Hospital for Rehabilitation - Occupational \\ Diseases, Ho Chi Minh City, Vietnam; \\ ${ }^{3}$ Woolcock Institute of Medical Research, \\ Hanoi, Vietnam
}

Correspondence: Quynh Ho Ngoc Huynh Faculty of Public Health, University of Medicine and Pharmacy, Ho Chi Minh City, Vietnam

Tel +84909592426

Fax +84-28 38552304

Email hhnquynhytcc@ump.edu.vn
Purpose: Little is known about the effect of COVID-19 pandemic on public health and preventive medicine students, particularly in resource-limited countries. This study evaluated stress level in this population in Vietnam and their coping strategies during the COVID-19 pandemic.

Patients and Methods: A cross-sectional study was conducted in April 2020 among 563 public health and preventive medicine students. A structured questionnaire included background information, the level of stress measured by the Perceived Stress Scale (PSS) and coping strategies evaluated by the Brief COPE. To compare the PSS score and Brief COPE score among participants with different characteristics, two-sided $t$ tests or ANOVA tests were used when appropriate.

Results: Most participants were females (71.4\%), and the mean age was 21.6 years old $(\mathrm{SD}=2.1)$. Almost all had moderate to high levels of knowledge, attitude and skill toward COVID-19 prevention and protection. The mean PSS score was 17.02 (SD 4.06), and more than $80 \%$ had a certain level of stress. The mean score of approach coping strategies was higher than avoidant coping strategies (2.74 and 1.84). Students with a high level of stress had a higher preference for avoidance coping strategies.

Conclusion: Although students reported relatively good knowledge, attitude and skill as well as the preference for adaptive coping strategies, they experienced a high level of stress during the COVID-19 pandemic.

Keywords: COVID-19, perceived stress, coping strategy, public health, preventive medicine, students

\section{Introduction}

In December 2019, the first cases of a respiratory illness caused by a novel corona virus (2019-nCoV, also known as COVID-19) were reported in Wuhan, Hubei Province, China. ${ }^{1}$ Since then, the disease has spread outside the Chinese border to other countries and regions. COVID-19 was officially declared as a global pandemic in March $2020^{2}$ which confirmed the danger of the disease to the human health and well-being. Until the time we conducted this study in May 2020, COVID-19 has occurred in over 200 countries and regions; 4 million cases were confirmed to be infected with COVID-19 and more than 278 thousand people died. ${ }^{3}$ In 2021, more than 100 million cases were confirmed worldwide. In Vietnam, the first COVID-19 case was reported in the early stage of the pandemic, on January 22nd, 2020. ${ }^{4}$ Although the outbreak has been under control with a low 
number of confirmed cases $(n=288)$ and no one dies of the disease, ${ }^{5}$ COVID-19 has put the entire country into pressure, affected both economic status and social activities. More than 30,000 people were quarantined at specific facilities and the government also ordered a nationwide social distancing for three weeks with strict regulations from April 1st, 2020.

The COVID-19 pandemic has been shown to have negative psychological impacts on otherwise healthy communities. ${ }^{6,7}$ Due to the sudden appearance and high level of transmission, the unavailability of definitive treatment and vaccination, the fear of the danger and unknown about COVID-19 result in psychological consequences such as anxiety, stress and other mental disorders. ${ }^{8}$ Strict policies such as quarantine or social distancing limit personal freedom which may also lead to negative effects on mental health and well-being. ${ }^{9}$ A web-based survey of 1091 respondents from 41 countries at the end of March 2020 showed a very high level of perceived stress, ${ }^{10}$ much higher than that reported in general population. In China, a study about the impact of COVID-19 epidemic among general population reported a prevalence of severe depressive, severe anxiety and severe stress of $16.5 \%, 28.8 \%$ and $8.1 \%$, respectively. ${ }^{11}$ High levels of perceived stress, anxiety and depression were also reported among the Italians. ${ }^{9,12}$ Young females who had low social economic status were found to be psychologically vulnerable to COVID-19. ${ }^{9,11-13}$ Notably, many suicides were reported in many countries, possibly due to the pressure from COVID-19 pandemic. ${ }^{14,15}$ A nationwide study among 10,067 individuals in Bangladesh reported a prevalence of suicidal ideation of $5 \%$ during the pandemic. ${ }^{16}$ However, little is known about the psychological effects of COVID-19 in Vietnam.

Recent studies have indicated that student's mental health can be strongly influenced by the COVID-19 pandemic. A study among 158 students aged 17 to 37 years in Kosovo revealed that $49.4 \%$ students had psychological distress, including $11.4 \%$ in severe condition. ${ }^{17}$ Anxiety has been found to be prevalent among students in many countries such as China, Indonesia, Taiwan and Thailand. ${ }^{18-20}$ Particularly, medical students were more vulnerable to the psychological impact of COVID-19 compared to other students. During the fight against the outbreak, they may have more specific pressures from school closure, the sense of responsibility in medical field, as well as readiness to support frontline. However, the lack of proper knowledge and skill can make them overestimate the situation, increase their stress and anxiety levels. ${ }^{21}$ A comparative study of Iranian society groups in COVID-19 pandemic revealed that the prevalence of stress, anxiety and depression in a medical student group was higher than students in other specialties. ${ }^{22}$ A study in Saudi Arabia during the MERS-CoV outbreak showed that female medical students had a higher stress level than males. ${ }^{23}$ Junior medical students were reported to have a higher anxiety level than their senior colleagues, despite having less contact with patients. ${ }^{24}$

Moreover, for those who had mental health problems during pandemics, coping strategies play an important role because this may lead to positive or negative mental health outcomes. Coping strategies include cognitive and behavioral efforts an individual uses to solve problems and to reduce the stress caused by these problems. ${ }^{25}$ On one hand, the proper use of coping strategies will help to manage stressful events and reduce negative emotions. On the other hand, inappropriate selection of coping strategies leads to severe stress or even suicide. A research about emotional responses and coping strategies of nurses and nursing college students during the COVID-19 outbreak in China found that both groups used problemfocused strategies more than emotion-focused strategies. ${ }^{26}$ This study also found that females were more likely to use problem-focused coping strategies and less likely to use emotional-focused coping strategies than males. ${ }^{26}$ Another study in Taiwan revealed that people with mental illness were likely to not adhere to preventive COVID-19 infection behaviors. ${ }^{27}$ However, coping strategies may also be affected by the culture and mental health literacy in different settings and countries. For example, in Vietnam, mental disorders have still been discriminated and people tend to select professional support as the last resort when their preferred source of support fails to help, or their mental health conditions become worse. A study among high school students indicated low level of mental health literacy and that students preferred non-professional support even when they had stress, anxiety and depression. $^{28}$ Therefore, coping strategies may be a problem in the era of social distancing due to COVID19 in Vietnam.

Since early March 2020, the University of Medicine and Pharmacy at Ho Chi Minh City (UMP HCMC) has organized many COVID-19 training courses to provide knowledge, skills and attitude toward the pandemic for all students. Particularly, the last year students participated in comprehensive online courses about COVID-19 
treatment, prevention and health education, so that they could be able to support medical staffs in the frontline when the outbreak became worse. Subsequently, several public health and preventive medicine students from UMP HCMC have voluntarily joined with Ho Chi Minh City Center for Disease Control to support in contact tracing of suspected and confirmed cases, detecting clusters, answering the hotline and classifying imported suspected cases. Because public health and preventive medicine students will soon become the key health workforce in the battle against pandemics, they may have a high level of stress due to the perception of responsibilities and social expectation. Without psychological preparation, training, and support early in the university, this workforce may become vulnerable in this current and possible future pandemics. However, to date, there is a lack of knowledge about the level of stress and coping strategies during pandemic among this future healthcare providers.

Therefore, this study aimed to evaluate the perceived stress level of public health and preventive medicine students and their coping strategies during the COVID-19 pandemic. The relationship between perceived stress and coping strategies was also explored. Findings from this study can help provide appropriate psychological supports or training for this population.

\section{Patients and Methods}

\section{Setting and Participants}

During a three-week period in April 2020, an online-based cross-sectional study was conducted at the UMP HCMC. This is among the major medical universities which provide medical and health science education for southern provinces in Vietnam. The Faculty of Public Health (FPH) where the study was conducted is among the seven faculties at UMP HCMC. At the Faculty of Public Health, there are two main programs including Bachelor of Public Health in 4 years and Doctor of Preventive Medicine in 6 years. At the time we conducted this study, there were about 900 students in these two programs. All the students were invited to participate in the survey, of which 628 agreed to participate. There were 65 students returned the questionnaire with substantial missing data for the main variables (ie, perceived stress and coping strategies) and were excluded from this analysis.

\section{Study Procedures}

All study procedures were approved by the Research Ethics Committee at UMP HCMC and were conducted in accordance with the Declaration of Helsinki. From an existing list of all public health and preventive medicine students at UMP, an email was sent to each individual student to inform about the study and to recruit the students. To ensure the security and confidentiality, LimeSurvey was used to host the online survey. Students who voluntarily agreed to participate in the study clicked on a link embedded with a unique access code. This token was to make sure only invited persons had access to the online form. By accessing to the online consent form, students agreed to this research privacy policy and allowed publishing their answers in this study without personal identified information. Participants were allowed to complete the survey once and thus multiple entry was not allowed. All participation was totally voluntary. Every five days, a reminder email was sent to participants who did not finish the survey. A maximum of three reminder emails were sent to participants during the survey.

\section{Measurement}

The online questionnaire contained three main parts. The first part included questions about background and demographic characteristics such as age, sex (male, female), living with whom (alone, with friends, with family, with relatives), study major (public health, preventive medicine), year of study, participating in any workshop about COVID-19 (yes, no). Participants were also asked to rate their knowledge, attitude and skill toward COVID-19 prevention and protection on a 10-point rating scale. A higher score indicates higher level of knowledge, positive attitude and skill. To facilitate data analysis, the score was then categorized into low (0-4), moderate (5-7) and high (8-10).

The second part was the Perceived Stress Scale (PSS). The PSS includes 10 questions using a 5-point Likert type rating scale from 0 (never) to 4 (very often) to measure the level of stress participants experienced in the past month. ${ }^{29}$ However, to reflect perceived stress during the COVID-19 pandemic, "you had the following experiences because of COVID-19" was added to the PSS. The total score of all 10 items is used to measure the level of perceived stress, a higher score indicates higher stress. The cut-offs of 13 and 26 were used to categorize the total score into low, moderate and high level of stress. ${ }^{30}$ This scale has been shown to have a high level of reliability and validity and has been used in a wide variety of populations and settings worldwide. ${ }^{30}$ The standard translation has been conducted 
and good psychometric properties of the PSS have been reported in Vietnam. ${ }^{31}$

The third part of the questionnaire was the Brief COPE which contains 28 coping strategies respondents did. ${ }^{32}$ To focus on the scope of this study, "during the COVID-19 pandemic" was added to the scale. Each item is rated on a 4-point Likert type rating scale from 1 (I have not been doing this at all) to 4 (I have been doing this a lot). The Brief COPE has 14 subscales capturing common coping strategies which are classified into two main strategies including avoidant coping and approach coping. The avoidant coping which is less effective in stress management is characterized by 6 subscales including self-distraction, denial, substance use, behavioral disengagement, venting, and self-blame. A more effective coping strategy is the approach coping or adaptive practical adjustment which consists of 6 subscales including active coping, use of emotional support, use of instrumental or informational support, positive reframing, planning and acceptance. The last 2 subscales including religion and humor are neither avoidant coping nor approach coping. The mean score of all items in each subscale is used and a higher number indicates higher preference for the coping strategies reported. The Brief COPE has been translated into different languages and validated in many populations. $^{33-35}$

In our study, the Brief COPE was translated into Vietnamese independently by two researchers who were fluent in English and the differences between these two translations were discussed in the presence of the principal investigator to decide the final version to be used. A pilot study was conducted among a convenient sample of five students to check the wording of the whole questionnaire before the main survey. In the main survey, both the PSS and the Brief COPE had good to excellent reliability with Cronbach's alpha of 0.79 and 0.87 , respectively.

\section{Data Analysis}

Frequencies and percentages were used to describe participants' characteristics. To measure the level of perceived stress and coping strategies based on the PSS score and the Brief COPE score, means with standard deviations or frequency distribution were used. To compare the PSS score and Brief COPE score among participants with different characteristics, two-sided $t$ tests or ANOVA tests were used when appropriate. To identify whether participants had preferences for avoidant coping or approach coping, the mean difference in these two subscales was used as an outcome and was analyzed using $t$ tests or ANOVA tests. The coping strategies based on the Brief COPE score between students with low and moderate stress were analyzed using $t$ tests. The choice of these statistics was based on the normal distribution of the data analyzed. Type one error rate of 5\% was used to indicate statistical significance. All data analyses were conducted using Stata version 16.

\section{Results}

Among 563 participants eligible in data analysis, most were females (71.4\%) with a mean age of 21.6 (standard deviation 2.1) years old. About three-fourths of participants were preventive medicine students. These characteristics were not different compared to 65 students who were excluded from the analysis. The majority of students reported having participated in workshops about COVID19. Although nearly $70 \%$ reported positive attitude toward COVID-19 prevention and protection, more than half had moderate or low level of knowledge and skills about this aspect (Table 1).

Table 2 presents the level of stress participants perceived in the last month because of COVID-19 pandemic. Participants reported a high level of stress in almost all questions in the PSS. Nearly one-third felt upset and about $60 \%$ felt angered, nervous and stressed during the last month. Based on the cut-off of 13 on the PSS, more than $80 \%$ participants were identified as having a certain level of stress because of COVID-19.

The mean score of approach coping strategies was higher than avoidant coping strategies (2.74 and 1.84) (Table 3). Among avoidant coping strategies, selfdistraction strategy including turning to work or other activities to take one mind off things and doing something to think about the problem less was the most common with a highest mean score of 2.89 (SD 0.68). In terms of approach coping, the most common preferences included acceptance (accepting the reality of the fact that the problem has happened and learning to live with the problem) and active coping (concentrating efforts on doing something about the situation and taking action to try to make the situation better) with the mean score on the Brief COPE of 3.15 (SD 0.69) and 3.00 (SD 0.67), respectively.

Table 4 presents the distribution of perceived stress and coping strategies among different participants' characteristics. Old participants who were in the last years at the university and those who had a low level of knowledge, attitude and skill toward COVID-19 prevention and 
Table I Characteristics of Public Health and Preventive Medicine Students $(\mathrm{N}=563)$

\begin{tabular}{|c|c|c|}
\hline Factor & Frequency & Percentage \\
\hline \multicolumn{3}{|l|}{ Sex } \\
\hline Male & 161 & 28.6 \\
\hline Female & 402 & 71.4 \\
\hline \multicolumn{3}{|l|}{ Age category (year) } \\
\hline$\leq 20$ & 195 & 34.6 \\
\hline $2 I-24$ & 320 & 56.8 \\
\hline$\geq 25$ & 48 & 8.5 \\
\hline \multicolumn{3}{|l|}{ Study major } \\
\hline Preventive medicine & 380 & 67.5 \\
\hline Public health & 183 & 32.5 \\
\hline \multicolumn{3}{|l|}{ Year of study } \\
\hline $\mathrm{I}-2$ & 228 & 40.5 \\
\hline $3-4$ & 210 & 37.3 \\
\hline $5-6$ & 125 & 22.2 \\
\hline \multicolumn{3}{|l|}{ Live with whom } \\
\hline Alone & 43 & 7.6 \\
\hline With friends & 164 & 29.1 \\
\hline With family & 325 & 57.7 \\
\hline With relatives & 31 & 5.5 \\
\hline \multicolumn{3}{|c|}{$\begin{array}{l}\text { Participated in any workshop } \\
\text { about COVID-19 }\end{array}$} \\
\hline Yes & 474 & 84.2 \\
\hline No & 89 & 15.8 \\
\hline \multicolumn{3}{|c|}{$\begin{array}{l}\text { Knowledge about COVID-19 } \\
\text { prevention and protection }\end{array}$} \\
\hline Low & 32 & 5.7 \\
\hline Moderate & 302 & 53.6 \\
\hline High & 229 & 40.7 \\
\hline \multirow{2}{*}{\multicolumn{3}{|c|}{$\begin{array}{l}\text { Positive attitude toward COVID- } \\
19 \text { prevention and protection }\end{array}$}} \\
\hline & & \\
\hline Low & 21 & 3.7 \\
\hline Moderate & 149 & 26.5 \\
\hline High & 393 & 69.8 \\
\hline \multicolumn{3}{|c|}{$\begin{array}{l}\text { Skill in COVID- } 19 \text { prevention and } \\
\text { protection }\end{array}$} \\
\hline Low & 60 & 10.7 \\
\hline Moderate & 283 & 50.3 \\
\hline High & 220 & 39.1 \\
\hline
\end{tabular}

protection reported significant higher level of perceived stress. Based on the difference on the Brief COPE score of approach coping and avoidance coping, old participants who did not participate in any workshop about COVID-19 and those who had low level of knowledge, good attitude and skill toward COVID-19 prevention and protection were less likely to choose approach coping strategies. In contrast, participants with high level of stress had a higher preference for avoidance coping strategies.

\section{Discussion}

In the early stage of COVID-19 pandemic in Vietnam, all schools and universities were closed except Hanoi Medical University and UMP HCMC. Students at UMP HCMC were provided with online and offline courses about COVID-19. This was to prepare the students for the worst condition when their contribution to the frontline of the battle against COVID-19 is needed. However, our study indicated that while public health and preventive medicine students had relatively good knowledge, attitude and skill in COVID-19 prevention and protection, they experienced extremely high level of stress. It is surprising that the high prevalence of stress was observed even when the students reported having used positive, approaching coping strategies during the outbreak.

The high level of stress found in our study is reasonable and is similar to those reported in previous studies. For example, using the same measurement scale (ie, PSS10) a study among Hong Kong healthcare students during the SARS outbreak in 2004 reported a mean score on the PSS of 18.4 (SD 4.6). ${ }^{36}$ Another study by Limcaoco, Mateos, Fernandez and Roncero ${ }^{10}$ in 1091 people in 41 countries indicated a mean score on the PSS of 17.4 ( SD = 6.4). This figure in our study $(\mathrm{M}=17.06, \mathrm{SD}=4.06)$ and in these two studies is very much higher compared to the cutoff of 13 normally used to identify those with stress. ${ }^{29}$ Other studies in various populations employing different measurement scales reported consistently high level of mental health problems such as that reported in college students in China during the COVID-19 outbreak. ${ }^{19,26,37}$ Similarly, compared to other studies conducted in medical students in Vietnam and other countries before the COVID-19 pandemic, the level of stress found our study is much higher. Pham, Bui, Nguyen, Nguyen, Tran, Vu and Dang $^{38}$ conducted a survey among 494 medical students at Hanoi Medical University and reported a prevalence of depression of $15.2 \%$. Quek, Tam, Tran, Zhang, Zhang, Ho and $\mathrm{Ho}^{39}$ revealed a globally pooled estimate of anxiety of $33.8 \%$ from a meta-analysis of 40,348 medical students. Although there were encouraging results from our study where students had positive responses for some items in the PPS such as "felt confident about your ability to handle personal problems", our findings and other evidence from 
Table 2 Perceived Stress Among Public Health and Preventive Medicine Students During COVID-19 Pandemic (N=563)

\begin{tabular}{|c|c|c|c|c|c|c|c|}
\hline \multirow{2}{*}{$\begin{array}{l}\text { In the Past Month, You Had the } \\
\text { Following Experiences Because of } \\
\text { COVID-19 }\end{array}$} & \multicolumn{5}{|c|}{ Distribution, n (\%) } & \multirow{2}{*}{$\begin{array}{r}\text { Mean } \\
\text { (Standard } \\
\text { Deviation) }\end{array}$} & \multirow{2}{*}{$\begin{array}{r}\text { Yes }^{2} \\
\text { n (\%) }\end{array}$} \\
\hline & Never & $\begin{array}{r}\text { Almost } \\
\text { Never }\end{array}$ & Sometimes & $\begin{array}{l}\text { Fairly } \\
\text { Often }\end{array}$ & $\begin{array}{l}\text { Very } \\
\text { Often }\end{array}$ & & \\
\hline $\begin{array}{l}\text { Been upset because of something that } \\
\text { happened unexpectedly }\end{array}$ & $59(10.5)$ & $132(23.4)$ & $292(51.9)$ & $71(12.6)$ & $9(1.6)$ & I.7I (0.87) & $372(66.1)$ \\
\hline $\begin{array}{l}\text { Felt that you were unable to control the } \\
\text { important things in your life }\end{array}$ & $81(14.4)$ & $228(40.5)$ & $200(35.5)$ & $45(8.0)$ & $9(1.6)$ & I.42 (0.89) & $254(45.1)$ \\
\hline Felt nervous and stressed & $70(12.4)$ & $161(28.6)$ & $263(46.7)$ & $55(9.8)$ & $14(2.5)$ & $1.61(0.91)$ & $332(59.0)$ \\
\hline $\begin{array}{l}\text { Felt confident about your ability to handle } \\
\text { your personal problems }\end{array}$ & $12(2.1)$ & $49(8.7)$ & $214(38.0)$ & $258(45.8)$ & $30(5.3)$ & $2.44(0.81)$ & $502(89.2)$ \\
\hline Felt that things were going your way & $23(4.1)$ & $103(18.3)$ & $281(49.9)$ & $144(25.6)$ & $12(2.1)$ & $2.03(0.83)$ & $437(77.6)$ \\
\hline $\begin{array}{l}\text { Found that you could not cope with all the } \\
\text { things that you had to do }\end{array}$ & $42(7.5)$ & $23 I(4 I .0)$ & $249(44.2)$ & $36(6.4)$ & $5(0.9)$ & $1.52(0.76)$ & $290(51.5)$ \\
\hline Been able to control irritations in your life & $25(4.4)$ & $53(9.4)$ & $192(34.1)$ & $246(43.7)$ & $47(8.3)$ & $2.42(0.93)$ & $485(86.2)$ \\
\hline Felt that you were on top of things & $22(3.9)$ & $79(14.0)$ & $270(48.0)$ & $177(3 \mid .4)$ & $15(2.7)$ & $2.15(0.83)$ & $462(82.1)$ \\
\hline $\begin{array}{l}\text { Been angered because of things that were } \\
\text { outside of your control }\end{array}$ & $49(8.7)$ & $166(29.5)$ & $267(47.4)$ & $65(11.5)$ & $16(2.8)$ & $1.70(0.89)$ & $348(61.8)$ \\
\hline $\begin{array}{l}\text { Felt difficulties were piling up so high that you } \\
\text { could not overcome them }\end{array}$ & $102(18.1)$ & $238(42.3)$ & $179(31.8)$ & $37(6.6)$ & $7(1.2)$ & $1.31(0.88)$ & $223(39.6)$ \\
\hline PSS score & & & & & & $17.06(4.06)$ & \\
\hline $\begin{array}{l}\text { Perceived stress category } \\
\text { Low } \\
\text { Moderate } \\
\text { High }\end{array}$ & & & & & & $\begin{array}{r}\mathrm{n}(\%) \\
96(17.1) \\
458(81.3) \\
9(1.6)\end{array}$ & \\
\hline
\end{tabular}

Notes: ${ }^{a}$ No $=$ Never, Almost never; Yes = Sometimes, Fairly often; Very often.

Table 3 Coping Strategies Among Public Health and Preventive Medicine Students During COVID-19 Pandemic ( $\mathrm{N}=563)$

\begin{tabular}{|l|r|r|}
\hline Brief COPE Subscales & Mean & Standard Deviation \\
\hline Avoidant coping & 1.84 & 0.44 \\
Self-distraction & 2.89 & 0.68 \\
Denial & 1.56 & 0.69 \\
Substance use & 1.10 & 0.36 \\
Behavioral disengagement & 1.57 & 0.64 \\
Venting & 2.06 & 0.72 \\
Self-blame & 1.88 & 0.83 \\
\hline Approach coping & 2.74 & 0.53 \\
Active coping & 3.00 & 0.67 \\
Use of emotional support & 2.38 & 0.86 \\
Use of instrumental support & 2.44 & 0.82 \\
Positive reframing & 2.94 & 0.75 \\
Planning & 2.55 & 0.65 \\
Acceptance & 3.15 & 0.69 \\
\hline Humor & 1.66 & 0.72 \\
\hline Religion & 1.83 & 0.89 \\
\hline
\end{tabular}

literature before and during the COVID-19 confirm the negative psychological effect of this pandemic.

To cope with stress due to COVID-19, a wide range of coping strategies have been reported. Although the patterns are different depending on the context, culture and the situation of an outbreak, the choice of positive and problem-oriented coping strategies was the most common in previous studies. ${ }^{26,36}$ In our study, participants were more likely to choose approach coping strategies such as active coping, acceptance or positive reframing. This can be explained by the fact that public health and preventive medicine students may have better knowledge and skills in dealing with health-related problems. This is true in previous studies in the absence of COVID-19. For example, while medical and healthcare students were reported to have good or positive coping strategies to overcome stress or mental health problems, ${ }^{40,41}$ students in other fields are more likely to choose maladaptive coping strategies. ${ }^{42}$ However, although high likelihood of choosing positive 
Table 4 Correlates of Perceived Stress and Coping Strategies Among Public Health and Preventive Medicine Students During COVID19 Pandemic $(\mathrm{N}=563)$

\begin{tabular}{|c|c|c|c|c|c|c|c|c|}
\hline \multirow[t]{2}{*}{ Factor } & \multicolumn{2}{|c|}{ PSS Score } & \multicolumn{2}{|c|}{ Avoidant Coping } & \multicolumn{2}{|c|}{$\begin{array}{l}\text { Approach } \\
\text { Coping }\end{array}$} & \multicolumn{2}{|c|}{ Difference $^{a}$} \\
\hline & $M(S D)$ & $p$ & $M(S D)$ & $\mathbf{p}$ & $M(S D)$ & $p$ & $M(S D)$ & $p$ \\
\hline \multicolumn{9}{|l|}{ Sex } \\
\hline Male & I6.75 (4.18) & 0.253 & $1.85(0.44)$ & 0.733 & $2.70(0.53)$ & 0.198 & $0.84(0.52)$ & 0.128 \\
\hline Female & $17.18(4.00)$ & & $\mathrm{I} .84(0.44)$ & & $2.76(0.53)$ & & $0.92(0.55)$ & \\
\hline \multicolumn{9}{|l|}{ Age category (year) } \\
\hline$\leq 20$ & $|6.4|(4.06)$ & 0.015 & $\mathrm{I} .77(0.4 \mathrm{I})$ & 0.006 & $2.7 \mid(0.54)$ & 0.375 & $0.94(0.5 \mathrm{I})$ & 0.031 \\
\hline $21-24$ & $17.34(4.05)$ & & $1.86(0.44)$ & & $2.77(0.53)$ & & $0.91(0.56)$ & \\
\hline$\geq 25$ & $17.83(3.8 I)$ & & $1.98(0.49)$ & & $2.69(0.48)$ & & $0.71(0.56)$ & \\
\hline \multicolumn{9}{|l|}{ Study major } \\
\hline Preventive medicine & $17.05(3.9 \mid)$ & 0.930 & $1.86(0.43)$ & 0.343 & $2.74(0.52)$ & 0.709 & $0.88(0.53)$ & 0.261 \\
\hline Public health & $17.08(4.35)$ & & $1.82(0.46)$ & & $2.76(0.55)$ & & $0.94(0.58)$ & \\
\hline \multicolumn{9}{|l|}{ Year of study } \\
\hline $\mathrm{I}-2$ & $16.36(3.96)$ & 0.002 & $1.79(0.43)$ & 0.051 & $2.74(0.54)$ & 0.760 & $0.95(0.5 \mathrm{I})$ & 0.130 \\
\hline $3-4$ & $17.42(4.10)$ & & $1.88(0.44)$ & & $2.76(0.52)$ & & $0.88(0.56)$ & \\
\hline $5-6$ & $17.74(3.99)$ & & $1.88(0.44)$ & & $2.72(0.5 \mathrm{I})$ & & $0.84(0.57)$ & \\
\hline \multicolumn{9}{|l|}{ Live with whom } \\
\hline Alone & $16.49(3.45)$ & 0.214 & $1.86(0.43)$ & 0.649 & $2.87(0.48)$ & 0.443 & I.0I (0.55) & 0.414 \\
\hline With friends & $17.50(3.84)$ & & $1.87(0.43)$ & & $2.74(0.53)$ & & $0.88(0.52)$ & \\
\hline With family & $17.00(4.2 I)$ & & $1.84(0.44)$ & & $2.73(0.54)$ & & $0.89(0.55)$ & \\
\hline With relatives & $16.13(4.16)$ & & $1.76(0.48)$ & & $2.74(0.47)$ & & $0.98(0.57)$ & \\
\hline \multicolumn{9}{|c|}{ Participated in any workshop about COVID-19 } \\
\hline Yes & $16.96(4.01)$ & 0.184 & $1.84(0.44)$ & 0.774 & $2.76(0.5 \mathrm{I})$ & 0.037 & $0.92(0.53)$ & 0.025 \\
\hline No & $17.58(4.28)$ & & $1.86(0.44)$ & & $2.64(0.58)$ & & $0.78(0.61)$ & \\
\hline \multicolumn{9}{|c|}{$\begin{array}{l}\text { Knowledge about COVID-19 prevention and } \\
\text { protection }\end{array}$} \\
\hline Low & $19.75(4.44)$ & $<0.001$ & $2.00(0.5 \mathrm{I})$ & 0.002 & $2.67(0.44)$ & 0.461 & $0.67(0.58)$ & $<0.001$ \\
\hline Moderate & $17.34(3.76)$ & & $1.88(0.43)$ & & $2.73(0.53)$ & & $0.85(0.5 \mathrm{I})$ & \\
\hline High & $16.31(4.18)$ & & $1.77(0.43)$ & & $2.77(0.54)$ & & $1.00(0.57)$ & \\
\hline \multicolumn{9}{|c|}{$\begin{array}{l}\text { Positive attitude toward COVID-19 } \\
\text { prevention and protection }\end{array}$} \\
\hline Low & $18.67(4.60)$ & 0.045 & $2.01(0.57)$ & 0.176 & $2.74(0.52)$ & 0.148 & $0.73(0.68)$ & 0.025 \\
\hline Moderate & $17.47(3.92)$ & & $1.85(0.42)$ & & $2.67(0.52)$ & & $0.82(0.55)$ & \\
\hline High & $16.82(4.05)$ & & $1.83(0.44)$ & & $2.77(0.53)$ & & $0.94(0.53)$ & \\
\hline \multicolumn{9}{|c|}{ Skill in COVID-1 9 prevention and protection } \\
\hline Low & $19.20(4.16)$ & $<0.001$ & $1.97(0.45)$ & 0.040 & $2.68(0.44)$ & 0.041 & $0.71(0.60)$ & $<0.001$ \\
\hline Moderate & $17.09(3.65)$ & & $1.84(0.42)$ & & $2.70(0.54)$ & & $0.86(0.49)$ & \\
\hline High & I6.44 (4.33) & & $\mathrm{I} .8 \mathrm{I}(0.45)$ & & $2.81(0.52)$ & & $1.00(0.58)$ & \\
\hline \multicolumn{9}{|l|}{ Perceived stress } \\
\hline Low & - & - & $1.57(0.35)$ & $<0.001$ & $2.66(0.59)$ & 0.229 & $1.09(0.50)$ & $<0.001$ \\
\hline Moderate & - & & $1.89(0.42)$ & & $2.76(0.5 \mathrm{I})$ & & $0.88(0.53)$ & \\
\hline High & - & & $2.56(0.49)$ & & $2.69(0.68)$ & & $0.14(0.91)$ & \\
\hline
\end{tabular}

Notes: ${ }^{\mathrm{a} D i f f e r e n c e}=$ Brief COPE score on the approach coping - Brief COPE score on the avoidance coping.

Abbreviations: PSS, Perceived Stress Scale; UMP HCMC, The University of Medicine and Pharmacy at Ho Chi Minh City. 
coping strategies was reported, participants had a high level of stress. This indicates the serious impact of COVID-19. Moreover, this also means that coping strategies used by public health and preventive medicine students are not enough and effective in preventing or overcoming stress. Our findings indicate an urgent need for psychological intervention and guidelines on stress reduction and how to cope with COVID-19 for this population. Moreover, because psychological resources are limited in Vietnam, intervention should target students who have high risk of stress and maladaptive coping strategies found in our study. As inspired by a previous study by Roll, Chiu and Huang, ${ }^{43}$ a reconstruction of curriculum with an addition of fundamental courses of COVID-19 is likely to be beneficial for public health and preventive medicine students during the pandemic.

Findings from our study should be interpreted in the presence of several limitations and cautions. Because COVID-19 is a rare pandemic in this century and stress, coping strategies are more situation dependent, we are not sure whether our findings are temporary. Although we hope that students' health will become normal once COVID-19 is eradicated, we do not know whether this pandemic and stress will result in long-term effect on students' health. Moreover, the absence of vaccine as relevant coping strategies and effective prevention for COVID-19 may also contribute to the high level of fear and stress during the pandemic. A previous study revealed that the availability of vaccination information might affect students' coping strategies. ${ }^{44}$ Therefore, further studies and interventions are needed, especially in the presence of an effective vaccine. Second, our study was conducted at one university in a single city which may limit the generalization of the findings. It is possible that students in other areas may have different levels of stress and coping strategies. More studies in different settings are needed. Third, the use of online survey to collect data might affect the response rate. However, due to social distancing, other data collecting methods were not possible. The validity of online survey and offline survey should be investigated in further studies. Moreover, the measures used in this study were not developed specifically for COVID-19 and thus other alternatives such as the Fear of COVID-19 Scale $^{45}$ or the COVID Stress Scale ${ }^{46}$ should be considered in future studies.

\section{Conclusion}

In conclusion, although public health and preventive medicine students reported relatively good knowledge, attitude and skill toward COVID-19 prevention and protection as well as the preference for positive, adaptive coping strategies, they experienced a high level of stress during the COVID-19 pandemic. These findings reveal a need for further studies and intervention for this population, especially those who have a higher risk of stress. Since the increased understanding about COVID-19 may help reduce the fear of it and thus reduce COVID-19 related stress, fundamental courses of COVID-19 are likely to be beneficial for this population.

\section{Acknowledgments}

The authors gratefully acknowledge the time and effort given by the public health and preventive medicine students and universities administrators to our studies.

\section{Disclosure}

The authors declare that there is no conflict of interest regarding the publication of this article.

\section{References}

1. Yang X, Yu Y, Xu J, et al. Clinical course and outcomes of critically ill patients with SARS-CoV-2 pneumonia in Wuhan, China: a single-centered, retrospective, observational study. Lancet Respir Med. 2020;8(5):475-481. doi:10.1016/S2213-2600(20)30079-5

2. World Health Organization. WHO director-general's opening remarks at the mission briefing on COVID-19-26 February 2020. Available from: https://www.who.int/dg/speeches/detail/who-director-general -s-opening-remarks-at-the-mission-briefing-on-covid-19-26february-2020. Accessed May, 10, 2020.

3. World Health Organization. Situation report - 112 - data as received by WHO from national authorities by 10:00 CEST, 11 May 2020. Available from: https://www.who.int/docs/default-source/coronavir use/situation-reports/20200511-covid-19-sitrep-112.pdf?sfvrsn= 813f2669_2. Accessed May 14, 2020.

4. Phan LT, Nguyen TV, Luong QC, et al. Importation and human-tohuman transmission of a novel coronavirus in Vietnam. $N$ Engl J Med. 2020;382(9):872-874. doi:10.1056/NEJMc2001272

5. Vietnam Ministry of Health. Information page about COVID-19. Available from: https://ncov.moh.gov.vn/. Accessed May 14, 2020.

6. Kelvin DJ, Rubino S. Fear of the novel coronavirus. J Infect Dev Ctries. 2020;14(1):1-2. doi:10.3855/jidc. 12496

7. Asmundson GJG, Taylor S. Coronaphobia: fear and the 2019-nCoV outbreak. J Anxiety Disord. 2020;70:102196. doi:10.1016/j.janxdis. 2020.102196

8. Shigemura J, Ursano RJ, Morganstein JC, Kurosawa M, Benedek DM. Public responses to the novel 2019 coronavirus (2019-nCoV) in Japan: mental health consequences and target populations. Psychiatry Clin Neurosci. 2020;74(4):281-282. doi:10. 1111/pen.12988

9. Flesia L, Fietta V, Colicino E, Segatto B, Monaro M Stable psychological traits predict perceived stress related to the COVID-19 outbreak. 2020 doi:10.31234/osf.io/yb2h8.

10. Limcaoco RSG, Mateos EM, Fernandez JM, Roncero C. Anxiety, worry and perceived stress in the world due to the COVID-19 pandemic, March 2020. Preliminary results. medRxiv. 2020;2020: 20043992. doi:10.1101/2020.04.03.20043992 
11. Wang C, Pan $\mathrm{R}$, Wan $\mathrm{X}$, et al. Immediate psychological responses and associated factors during the initial stage of the 2019 Coronavirus Disease (COVID-19) epidemic among the general population in China. Int J Environ Res Public Health. 2020;17(5). doi:10.3390/ ijerph17051729

12. Rossi R, Socci V, Talevi D, et al. COVID-19 pandemic and lockdown measures impact on mental health among the general population in Italy. An $\mathrm{N}=18147$ web-based survey. medRxiv. 2020;2020:20057802. doi:10.1101/2020.04.09.20057802

13. Huang Y, Zhao N. Generalized anxiety disorder, depressive symptoms and sleep quality during COVID-19 epidemic in China: a web-based cross-sectional survey. medRxiv. 2020;2020:20025395. doi:10.1101/2020.02.19.20025395

14. Thakur V, Jain A. COVID 2019-suicides: a global psychological pandemic. Brain Behav Immun. 2020;S0889-1591(20)30643-7. doi:10.1016/j.bbi.2020.04.062

15. Gunnell D, Appleby L, Arensman E, et al. Suicide risk and prevention during the COVID-19 pandemic. Lancet Psychiatry. 2020;7 (6):468-471. doi:10.1016/s2215-0366(20)30171-1

16. Mamun MA, Sakib N, Gozal D, et al. The COVID-19 pandemic and serious psychological consequences in Bangladesh: a population-based nationwide study. J Affect Disord. 2021;279:462-472. doi:10.1016/j. jad.2020.10.036

17. Arenliu A, Bërxulli D. Rapid assessment: psychological distress among students in Kosovo during the COVID 19 pandemic. 2020.

18. Yang H, Bin P, He AJ. Opinions from the epicenter: an online survey of university students in Wuhan amidst the COVID-19 outbreak1. J Chin Gov. 2020;1-15. doi:10.1080/23812346.2020.1745411

19. Cao W, Fang Z, Hou G, et al. The psychological impact of the COVID-19 epidemic on college students in China. Psychiatry Res. 2020;287:112934. doi:10.1016/j.psychres.2020.112934

20. Pramukti I, Strong C, Sitthimongkol Y, et al. Anxiety and suicidal thoughts during the COVID-19 pandemic: Cross-country comparative study among Indonesian, Taiwanese, and Thai University students. J Med Internet Res. 2020;22(12):e24487. doi:10.2196/ 24487

21. Kim JS, Choi JS. Middle East respiratory syndrome-related knowledge, preventive behaviours and risk perception among nursing students during outbreak. J Clin Nurs. 2016;25(17-18):2542-2549. doi:10.1111/jocn. 13295

22. Vahedian Azimi A, Moayed M, Rahimibashar F, Shojaei S, Ashtari S, Pourhoseingholi MA. Compare the severity of psychological distress among four groups of Iranian Society in COVID-19 pandemic. 2020.

23. Al-Rabiaah A, Temsah M-H, Al-Eyadhy AA, et al. Middle East Respiratory Syndrome-Corona Virus (MERS-CoV) associated stress among medical students at a university teaching hospital in Saudi Arabia. J Infect Public Health. 2020;13(5):687-691. doi:10.1016/j. jiph.2020.01.005

24. Khalid I, Khalid TJ, Qabajah MR, Barnard AG, Qushmaq IA. Healthcare workers emotions, perceived stressors and coping strategies during a MERS-CoV outbreak. Clin Med Res. 2016;14(1):7-14. doi:10.3121/cmr.2016.1303

25. Algorani EB, Gupta V. Coping mechanisms. In: StatPearls [Internet]. Treasure Island (FL): StatPearls Publishing.2021,2-3. https://www. ncbi.nlm.nih.gov/books/NBK559031/. Accessed May 28, 2021.

26. Huang L, Xu F, Liu HR. Emotional responses and coping strategies of nurses and nursing college students during COVID-19 outbreak medRxiv. 2020;2020:20031898. doi:10.1101/2020.03.05.20031898

27. Chang K-C, Strong C, Pakpour AH, Griffiths MD, Lin C-Y. Factors related to preventive COVID-19 infection behaviors among people with mental illness. J Formos Med Assoc. 2020;119(12):1772-1780. doi:10.1016/j.jfma.2020.07.032

28. Thai TT, Vu NLLT, Bui HHT. Mental health literacy and help-seeking preferences in high school students in Ho Chi Minh City, Vietnam. School Ment Health. 2020;12(2):378-387. doi:10.10 07/s12310-019-09358-6
29. Cohen S, Kamarck T, Mermelstein R. A global measure of perceived stress. J Health Soc Behav. 1983;24(4):385-396. doi:10.2307/ 2136404

30. Lee EH. Review of the psychometric evidence of the perceived stress scale. Asian Nurs Res. 2012;6(4):121-127. doi:10.1016/j.anr.2012. 08.004

31. Dao-Tran TH, Anderson D, Seib C. The Vietnamese version of the Perceived Stress Scale (PSS-10): translation equivalence and psychometric properties among older women. BMC Psychiatry. 2017;17 (1):53. doi:10.1186/s12888-017-1221-6

32. Carver CS. You want to measure coping but your protocol's too long: consider the brief COPE. Int J Behav Med. 1997;4(1):92-100. doi:10.1207/s15327558ijbm0401_6

33. Garcia FE, Barraza-Pena CG, Wlodarczyk A, Alvear-Carrasco M, Reyes-Reyes A. Psychometric properties of the Brief-COPE for the evaluation of coping strategies in the Chilean population. Psicol Reflex Crit. 2018;31(1):22. doi:10.1186/ s41155-018-0102-3

34. Peters RM, Solberg MA, Templin TN, Cassidy-Bushrow AE. Psychometric properties of the brief COPE among pregnant African American women. West J Nurs Res. 2020;42(11):193945920907686. doi:10.1177/0193945920907686

35. Mohanraj R, Jeyaseelan V, Kumar S, et al. Cultural adaptation of the brief COPE for persons living with HIV/AIDS in southern India. AIDS Behav. 2015;19(2):341-351. doi:10.1007/s10461-0140872-2

36. Wong JG, Cheung EP, Cheung V, et al. Psychological responses to the SARS outbreak in healthcare students in Hong Kong. Med Teach. 2004;26(7):657-659. doi:10.1080/01421590400006572

37. Wu W, Zhang Y, Wang P, et al. Psychological stress of medical staffs during outbreak of COVID-19 and adjustment strategy. J Med Virol. 2020;92(10):1962-1970. doi:10.1002/jmv.25914

38. Pham T, Bui L, Nguyen A, et al. The prevalence of depression and associated risk factors among medical students: an untold story in Vietnam. PLoS One. 2019;14(8):e0221432-e0221432. doi:10.1371/ journal.pone.0221432

39. Quek Q, Tam T, Tran T, et al. The global prevalence of anxiety among medical students: a meta-analysis. Int J Environ Res Public Health. 2019;16(15):2735. doi:10.3390/ijerph16152735

40. Singh S, Prakash J, Das RC, Srivastava K. A cross-sectional assessment of stress, coping, and burnout in the final-year medical undergraduate students. Ind Psychiatry J. 2016;25(2):179-183. doi:10.4103/ipj.ipj $68 \quad 16$

41. Al-Dubai SAR, Al-Naggar RA, Alshagga MA, Rampal KG. Stress and coping strategies of students in a medical faculty in Malaysia. Malays J Med Sci. 2011;18(3):57-64.

42. Mahmoud JS, Staten R, Hall LA, Lennie TA. The relationship among young adult college students' depression, anxiety, stress, demographics, life satisfaction, and coping styles. Issues Ment Health Nurs. 2012;33(3):149-156. doi:10.3109/01612840.2011. 632708

43. Roll R, Chiu M, Huang C. Answering the call to action: COVID-19 curriculum design by students for students. Acad Med. 2020;95(11): e6. doi:10.1097/ACM.0000000000003588

44. Wang P-W, Ahorsu DK, Lin C-Y, et al. Motivation to have COVID-19 vaccination explained using an extended protection motivation theory among university students in China: the role of information sources. Vaccines. 2021;9(4):380. doi:10.3390/vaccines9040380

45. Ahorsu DK, Lin C-Y, Imani V, Saffari M, Griffiths MD, Pakpour AH. The fear of COVID-19 scale: development and initial validation. Int $J$ Ment Health Addict. 2020;1-9. doi:10.1007/s11469-02000270-8

46. Taylor S, Landry CA, Paluszek MM, Fergus TA, McKay D, Asmundson GJG. Development and initial validation of the COVID stress scales. J Anxiety Disord. 2020;72:102232. doi:10.1016/j. janxdis.2020.102232 


\section{Publish your work in this journal}

Psychology Research and Behavior Management is an international, peer-reviewed, open access journal focusing on the science of psychology and its application in behavior management to develop improved outcomes in the clinical, educational, sports and business arenas. Specific topics covered in the journal include: Neuroscience, memory and decision making; Behavior modification and management; Clinical applications; Business and sports performance management; Social and developmental studies; Animal studies. The manuscript management system is completely online and includes a very quick and fair peer-review system, which is all easy to use. Visit http://www. dovepress.com/testimonials.php to read real quotes from published authors. 